Part of Journal of Research of the National Bureau of Standards, Volume 25, September 1940

\title{
THICKNESS OF A LIQUID FILM ADHERING TO A SURFACE SLOWLY WITHDRAWN FROM THE LIQUID
}

\author{
By Francis C. Morey
}

\section{ABSTRACT}

When a solid body is immersed in a bath of liquid and withdrawn, a film of the liquid adheres to the solid surface and gradually drains back into the bath when the motion ceases. The relationship existing between the average film thickness, the speed of withdrawal, and the kinematic viscosity of the liquid is the subject dealt with in this paper.

According to the generally accepted theory the film thickness varies with the square root of the product of the speed and the kinematic viscosity. It was noticed that corrections based on this relationship and used in the calibration of a gas-measuring standard were not satisfactory. Therefore an experimental apparatus was designed to test the theory. Analysis of the data revealed that within the range of speeds used the theory does not correctly predict the film thickness, and an empirical equation of the form

$$
t=k(\nu s)^{n}
$$

was employed, in which $t$ is the average film thickness, $\nu$ is the kinematic viscosity of the liquid, $s$ is the speed of withdrawal of the surface, $k$ and $n$ are quantities varying slightly with the liquid used. The approximate values of $k$ and $n$ found by experiment are 0.015 and 0.63 , respectively.

Nine liquids were tested, including mineral, vegetable, and animal oils, and synthetic organic compounds of oily nature.

\section{CONTENTS}

I. Introduction

385

II. Experimental apparatus

III. Data and analysis

IV. Conclusions _.

\section{INTRODUCTION}

When a solid surface such as a sheet of metal is withdrawn from a bath of liquid, a thin film of the liquid is carried up with the solid and adheres to it, gradually draining back into the bath if the motion of the plate ceases. In many experiments with physical apparatus it is desirable to know how the thickness of such a film is related to the properties of the liquid and to the speed of withdrawal. Need of such information has occurred in the field of gas measurements, where gas volumes are determined by the displacement of the cylindrical bell of a gas holder moving in a liquid sealing bath. The Stillman portable cubic-foot standard and the gas-meter prover are examples. 
Often the liquid film is of negligible volume, especially when the speed of withdrawal is small and where liquids of low viscosity may be used. Research in the method of testing Stillman standards has indicated the desirability of using oil of low vapor pressure as a sealing medium. Such oils have relatively high viscosity, and hence we are faced with the necessity of making small volume corrections due to the oil which adheres to the drum of the instrument.

In reviewing the literature on the subject, it was found that the problem has been investigated by the Research Staff of the General Electric Co. of London, ${ }^{1}$ who found that the thickness follows the equation

where

$$
t=\sqrt{\frac{2 v_{0} \eta}{\rho g}}
$$

$t=$ the thickness of the film near the surface of the bath,

$v_{0}=$ the speed of withdrawal,

$\eta=$ the absolute viscosity of the liquid,

$\rho=$ the density of the liquid,

$g=$ acceleration due to gravity.

This equation is said to apply to a smooth plate of infinite breadth, but will fit the practical case of a cylinder provided the radius of the cylinder is very much greater than the film thickness. The nature of the surface withdrawn is thought to have no importance if the surface irregularities are small relative to film thickness (that is, the surface should be smooth and polished).

Mathematical investigations of the profile of a draining film have been conducted by $\mathrm{H}$. Jefferys, ${ }^{2}$ which indicate that the profile of the film is parabolic, at least near the top of the wetted portion. This conclusion has been substantiated by the experimental work of Satterly and associates. ${ }^{3456} 78$

Additional refinements in the theory have been suggested by Green ${ }^{9}$ to account for slight discrepancies observed near the upper boundary of the film.

Use of the equation stated above to compute the correction to apply in calibrating a cubic-foot standard was not entirely satisfactory, and it was therefore decided to attempt to check the equation using the oil selected as a sealing medium. This is a water-white petroleum oil having an absolute viscosity of about 0.24 poise at $25^{\circ} \mathrm{C}$ and a density of $0.841 \mathrm{~g} / \mathrm{ml}$. It was later decided to extend the investigation to include three other petroleum oils and representative vegetable and animal oils and synthetic organic substances of oily nature.

\footnotetext{
1 Goucher and Ward, Phil. Mag. [6] 44, 1002 (1922).

2 H. Jefferys, Proc. Cambridge Phil. Soc. 26, 204 (1930).

3 Satterly and Mills, Trans. Roy. Soc. Can. 21, 277 (1927).

- Satterly and Turnbull, Trans. Roy. Soc. Can. 23, 95 (1929).

5 Satterly and Douglass, Trans. Roy. Soc. Can. 24, 87 (1930)

6 Satterly and Collingwood, Trans. Roy. Soc. Can. 25, 215 (1931).

7 Satterly and Stucky, Trans. Roy. Soc. Can. 26, 131 (1932).

8 Satterly and Givens, Trans. Roy. Soc. Can. 27, 145 (1933)

- G. Green, Phil. Mag. [6] 22, 730 (1936).
} 


\section{EXPERIMENTAL APPARATUS}

Figure 1 is a schematic diagram of the apparatus used. Determination of the quantity of oil adhering to the surface was accomplished by weighing. A thin brass cylinder, $T$, approximately 6.5 $\mathrm{cm}$ in diameter and $27 \mathrm{~cm}$ in length, was constructed from brass shim stock $0.013 \mathrm{~cm}$ thick. The joint was carefully soldered, and the cylinder was polished inside and outside. It was suspended beneath the table from one arm of an analytical balance, $W$, by means of a fine wire passing through small holes in the case and table so as to

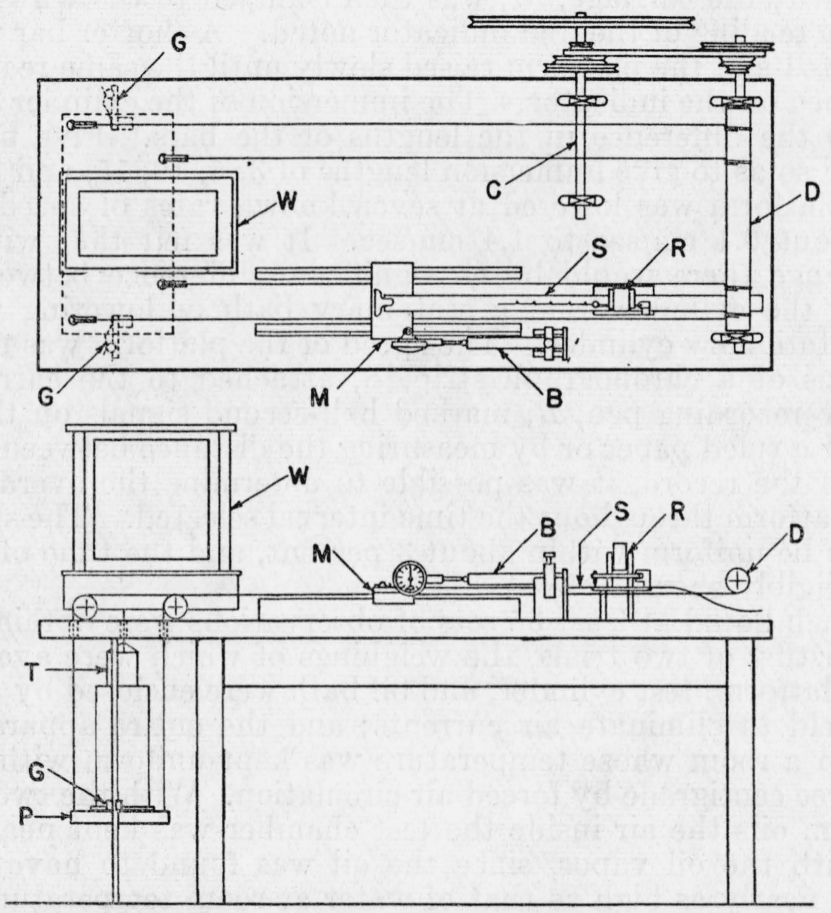

FigURe 1.-Schematic diagram of apparatus.

dip into an oil bath carried on a movable platform, $P$. The clean, dry cylinder was counterbalanced by a tare weight.

The platform, $P$, was supported by four strands of piano wire which passed over pulleys and were attached to the hoisting drum, $D$. The drum was driven by a four-step cone pulley and V-belt speed changer from a countershaft, $C$. The countershaft was belted to the motor drive, which consisted of a $1 / 4$-horsepower electric motor operating through a worm-speed reducer to deliver approximately $15 \mathrm{rpm}$. With such reduction in speed the motor was running practically idle, and changes in frictional resistance or in the load on the platform could not greatly affect the speed or the starting time of the motor. 
The platform was guided by two spring friction clamps, $G$, which operated on vertical rods. This eliminated swinging of the platform and damped out most of the vibrations introduced by the motor drive.

In order to control the length of travel of the platform, a carriage, $M$, was mounted on parallel ways and attached by means of a clamping bar to two of the piano wires supporting the platform. To this carriage was bolted a dial indicator in a horizontal position, so as to contact a bar of steel, $B$, of known length. The platform was raised very slowly until contact of the oil with the test cylinder was just established; the carriage, $M$, was then clamped to the wires and the reference reading of the dial indicator noted. A shorter bar was then substituted and the platform raised slowly until the same reading was established on the indicator. The immersion of the cylinder was then equal to the difference in the lengths of the bars. Five bars were provided so as to give immersion lengths of $3,5,10,15$, and $25 \mathrm{~cm}$.

The platform was lowered at seven known rates of speed ranging from about $0.1 \mathrm{~cm} / \mathrm{sec}$ to $1.4 \mathrm{~cm} / \mathrm{sec}$. It was felt that within this speed range there would be no significant difference between withdrawing the cylinder from a stationary bath or lowering the bath from a stationary cylinder. The speed of the platform was measured by means of a chronograph strip, $S$, attached to the carriage. A magnetic recording pen, $R$, marked half-second signals on this strip. By using a ruled paper or by measuring the distance between any two marks of the record, it was possible to determine the average speed of the platform throughout the time interval selected. The speed was found to be uniform within about 3 percent, and the time of starting was negligibly short.

For each liquid at least 35 sets of observations were obtained, each set consisting of two trials, the weighings of which were averaged.

The platform, test cylinder, and oil bath were enclosed by a removable shield to eliminate air currents; and the entire apparatus was placed in a room whose temperature was kept uniform within about one degree centigrade by forced air circulation. With the two lightest petroleum oils the air inside the test chamber was kept nearly saturated with the oil vapor, since the oil was found to have a vapor pressure nearly as high as that of water at room temperature. This procedure largely eliminated evaporation of the film from the test cylinder during weighing.

\section{DATA AND ANALYSIS}

Data on the behavior of nine liquids were obtained. Four of these were petroleum oils, three were synthetic organic compounds, one was a vegetable oil, and two were oils of animal origin. These liquids, with their viscosities and densities, are listed in table 1. Mineral oils 1 and 3 were water-white oils, and number 2 was a blend of these two. Number 4 was a commercial automobile engine oil. 
TABLE 1.-Densities and kinematic viscosities of the liquids tested

\begin{tabular}{|c|c|c|c|c|}
\hline \multirow[b]{2}{*}{ Liquid } & \multicolumn{2}{|c|}{$20^{\circ} \mathrm{C}$} & \multicolumn{2}{|c|}{$30^{\circ} \mathrm{C}$} \\
\hline & Density & $\begin{array}{l}\text { Kinematic } \\
\text { viscosity a }\end{array}$ & Density & $\begin{array}{l}\text { Kinematic } \\
\text { viscosity } ~\end{array}$ \\
\hline $\begin{array}{l}\text { Mineral oil } 1 \\
\text { Mineral oil } 2 \\
\text { Mineral oil } 3 \\
\text { Mineral oil } 4 \\
\text { Dibutyl phthalate } \\
\text { Aroclor (chlorinated diphenyl) } \\
\text { Peanut oil } \\
\text { Sperm oil } \\
\text { Lard oil }\end{array}$ & $\begin{array}{r}g / m l \\
0.7862 \\
.8336 \\
.8445 \\
.9009 \\
1.0464 \\
.1 .3853 \\
0.9143 \\
.8794 \\
.9140\end{array}$ & $\begin{array}{c}\text { Stokes } \\
0.02526 \\
.1820 \\
.3685 \\
\text { i. } 003 \\
0.1926 \\
.6345 \\
.8949 \\
.4062 \\
1.064\end{array}$ & $\begin{array}{r}g / m l \\
0.7790 \\
.8268 \\
.8377 \\
.8946 \\
1.0382 \\
1.3757 \\
0.9075 \\
.8727 \\
.9072\end{array}$ & $\begin{array}{c}\text { Stokes } \\
0.02049 \\
. .235 \\
.2306 \\
.5387 \\
.1275 \\
.2765 \\
.5806 \\
.2800 \\
.6749\end{array}$ \\
\hline
\end{tabular}

a Accuracy about 0.3 percent relative to the value of 0.01005 poise for the absolute viscosity of water at $20^{\circ} \mathrm{C}$.

Preliminary examination of the data revealed that an equation of the type

$$
t=k^{\prime}(\nu s)^{n}
$$

could be used to represent the results, wherein

$t=$ average film thickness, computed from the observed weight and known density of the oil, and the dimensions of the test cylinder.

$\nu=$ kinematic viscosity of the liquid

$s=$ speed of withdrawal.

$n, k^{\prime}=$ quantities which are nearly constant but which change slightly with the nature of the liquid.

Figure 2 is a graph of the data in which $\log t$ has been plotted against $\log (\nu s)$. It will be noted that the data for the different liquids overlaps; liquids of low viscosity at higher speeds yielded the same results as more viscous ones in which the withdrawal was slower. The slope of the lines is about 0.63 , and the value of $k^{\prime}$ as determined from the intercept is about 0.015 .

In order to compare the equation constants of the different liquids, the values of $n$ were computed for each liquid, using the method of least squares. Table 2 presents the results. The coefficient $k^{\prime}$ was next computed, using the average slope for each liquid and the coordinates of the mean point of each set of observations. The results are shown in table 3 .

TABLE 2.-Summary of values of $n$

\begin{tabular}{|c|c|c|c|c|c|c|}
\hline \multirow{2}{*}{ Liquid } & \multicolumn{5}{|c|}{ Length of immersion } & \multirow{2}{*}{$\begin{array}{c}\text { Average } \\
\text { value }\end{array}$} \\
\hline & $3 \mathrm{~cm}$ & $5 \mathrm{~cm}$ & $10 \mathrm{~cm}$ & $15 \mathrm{~cm}$ & $25 \mathrm{~cm}$ & \\
\hline $\begin{array}{l}\text { Mineral oil 1 } \\
\text { Mineral oil 2 } \\
\text { Mineral oil } 3 \\
\text { Mineral oil 4 } \\
\text { Dibutyl phthalate } \\
\text { Aroclor } \\
\text { Peanut oil } \\
\text { Sperm oil } \\
\text { Lard oil }\end{array}$ & $\begin{array}{l}0.638 \\
.642 \\
.641 \\
.647 \\
.624 \\
.633 \\
.616 \\
.627 \\
.620\end{array}$ & $\begin{array}{l}0.650 \\
.645 \\
.644 \\
.644 \\
.623 \\
.630 \\
.623 \\
.632 \\
.616\end{array}$ & $\begin{array}{r}0.647 \\
.650 \\
.645 \\
.641 \\
.619 \\
.632 \\
.622 \\
.632 \\
.621\end{array}$ & $\begin{array}{l}0.643 \\
.646 \\
.644 \\
.639 \\
.617 \\
.630 \\
.628 \\
.631 \\
.620\end{array}$ & $\begin{array}{l}0.640 \\
.642 \\
.644 \\
.641 \\
.622 \\
.630 \\
.626 \\
.633 \\
.612\end{array}$ & $\begin{array}{r}0.644 \\
.645 \\
.644 \\
.642 \\
.621 \\
.631 \\
.623 \\
.631 \\
.618\end{array}$ \\
\hline
\end{tabular}




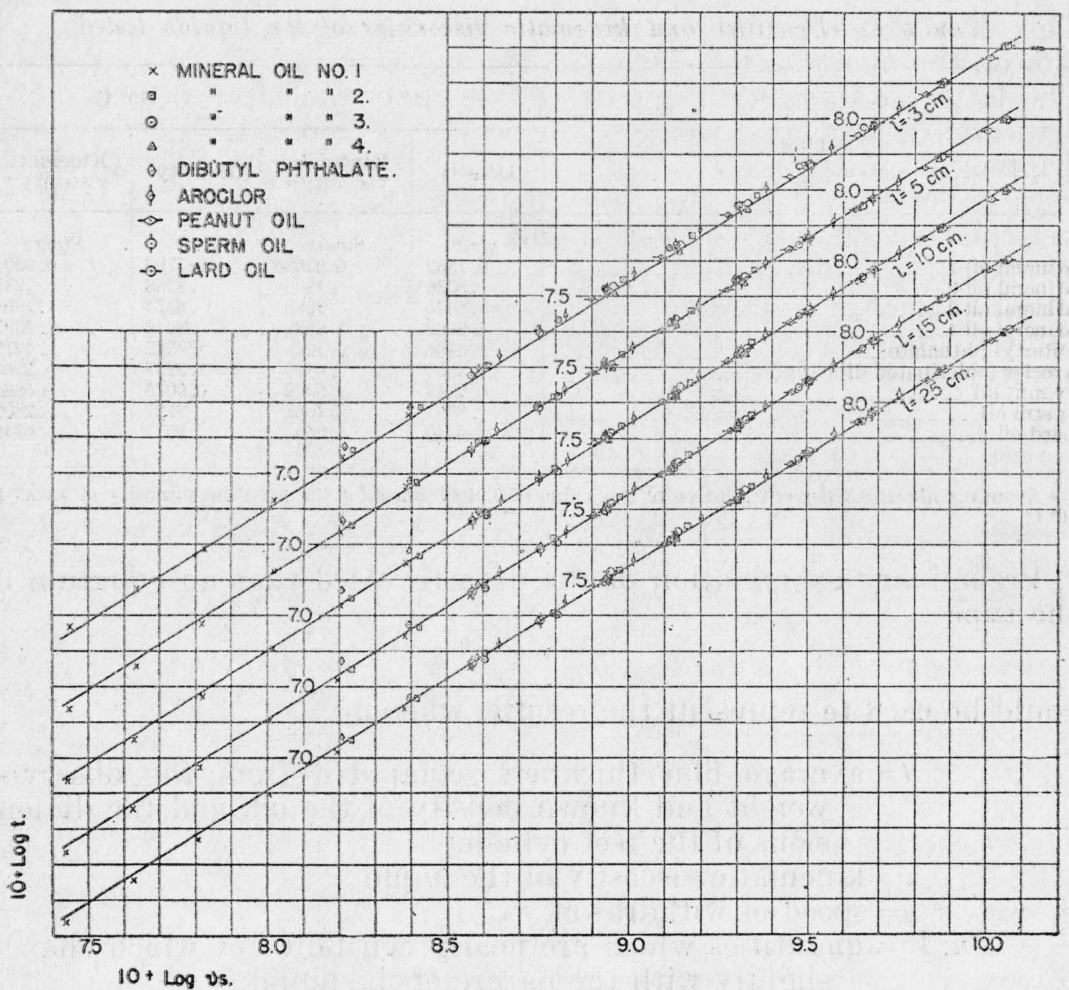

FIGURE 2.-Graph of observed film thiclnesses.

TABLE 3.-Summary of values of $k^{\prime}$

\begin{tabular}{|c|c|c|c|c|c|}
\hline \multirow{2}{*}{ Liquid } & \multicolumn{5}{|c|}{ Length of immersion } \\
\hline & $3 \mathrm{~cm}$ & $5 \mathrm{~cm}$ & $10 \mathrm{~cm}$ & $15 \mathrm{~cm}$ & $25 \mathrm{ctn}$ \\
\hline $\begin{array}{l}\text { Mineral oil } 1 \\
\text { Mineral oil } 2 \\
\text { Mineral oil } 3 \\
\text { Mineral oil } 4 \\
\text { Dibutyl phthalate } \\
\text { Aroclor } \\
\text { Peanut oil } \\
\text { Sperm oil } \\
\text { Lard oil }\end{array}$ & $\begin{array}{r}0.01585 \\
.01589 \\
.01600 \\
.01500 \\
.01521 \\
.01541 \\
.01502 \\
.01520 \\
.01497\end{array}$ & $\begin{array}{l}0.01544 \\
.01561 \\
.01552 \\
.01487 \\
.01499 \\
.01518 \\
.01478 \\
.01494 \\
.01479\end{array}$ & $\begin{array}{r}0.01518 \\
.01549 \\
.01521 \\
.01485 \\
.01495 \\
.01502 \\
.01470 \\
.01484 \\
.01465\end{array}$ & $\begin{array}{r}0.01520 \\
.01546 \\
.01505 \\
.01490 \\
.01483 \\
.01502 \\
.01667 \\
.01482 \\
.01463\end{array}$ & $\begin{array}{r}0.01517 \\
.01542 \\
.01497 \\
.01492 \\
.01467 \\
.01503 \\
.01462 \\
.01477 \\
.01468\end{array}$ \\
\hline
\end{tabular}

The values of $k^{\prime}$ will be seen to decrease, in general, as the length of immersion increases. This suggests a small correction on the length which is partly due to the capillary elevation of the surface of the liquid where it contacts the test cylinder. This elevation increases the wetted length slightly, and naturally will be of greatest relative importance where the immersion distance is least. Another reason for this correction is that a small amount of liquid adheres to the lower edge of the cylinder in the form of a drop when the film breaks away from the bath. The amount of liquid retained in this fashion is probably quite small, since the thickness of the metal is only $0.013 \mathrm{~cm}$. 
This drop should not be confused with that which forms as the oil film on the metal surface drains down and clings to the bottom edge. The latter accumulation is part of the film whose thickness is to be determined, and the weighing must be accomplished before any dripping occurs.

In order to evaluate the correction to be applied, the values of $k^{\prime}$ were plotted against the reciprocal of the wetted length, as illustrated in figure 3. The points may be fairly well represented by straight lines, which when extrapolated to obtain the zero intercept give the value of the constant for a theoretical infinite wetted length. This intercept will be denoted by $k$.

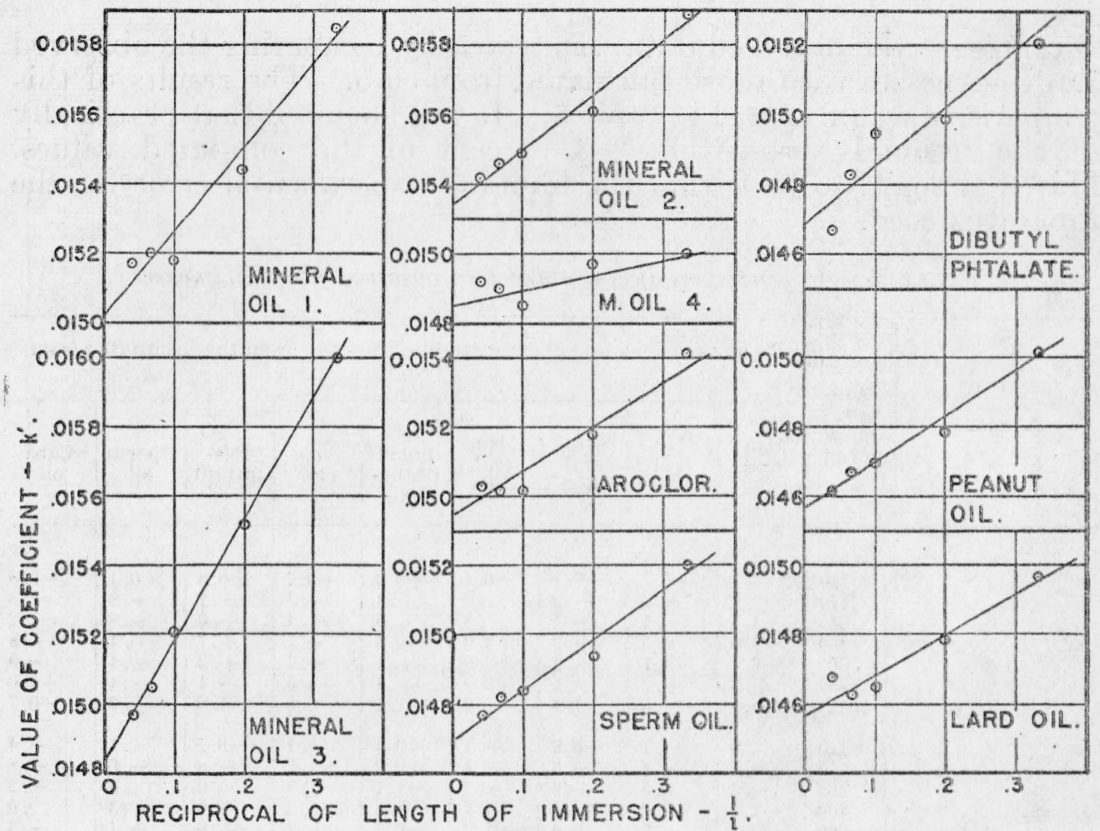

FIGUBE 3.-Variation of coefficient $k^{\prime}$ with length of immersion.

The correction term may now be written in the form $(l+b) / l$, where $l$ is the measured immersion length and $b$ is a constant depending upon the kind of liquid used. Thus, by definition,

$$
\left(\frac{l+b}{l}\right) k=k^{\prime} .
$$

Also, from the graphs of figure 3 ,

$$
k^{\prime}=m \frac{1}{l}+k,
$$

in which $m$ is the slope of the line. By eliminating $k^{\prime}$ between these equations and solving for $b$, it is readily shown that

$$
b=\frac{m}{k} .
$$

The values of $k$ and $b$ obtained for the liquids tested are shown in table 4. 
TABLE 4.-Summary of equation constants

\begin{tabular}{|c|c|c|c|c|c|c|c|}
\hline Liquid & $k$ & $b$ & $n$ & Liquid & $k$ & $b$ & $n$ \\
\hline $\begin{array}{l}\text { Mineral oil 1 } \\
\text { Mineral oil } 2 \\
\text { Mineral oil } 3 \\
\text { Mineral oil } 4 \\
\text { Dibutyl phthalate }\end{array}$ & $\begin{array}{l}0.01502 \\
.01534 \\
.01483 \\
.01485 \\
.01469\end{array}$ & $\begin{array}{l}0.158 \\
.102 \\
.236 \\
.003 \\
.109\end{array}$ & $\begin{array}{l}0.644 \\
.645 \\
.644 \\
.642 \\
.621\end{array}$ & $\begin{array}{l}\text { Aroclor } \\
\text { Peanut oil } \\
\text { Sperm oil } \\
\text { Lard oil }\end{array}$ & $\begin{array}{l}0.01495 \\
.01457 \\
.01470 \\
.01457\end{array}$ & $\begin{array}{l}0.083 \\
.088 \\
.096 \\
.078\end{array}$ & $\begin{array}{r}0.631 \\
.623 \\
.631 \\
.618\end{array}$ \\
\hline
\end{tabular}

The ability of the equation

$$
t=k \frac{l+b}{l}(\nu s)^{n}
$$

to represent the observed data was tested by comparing the observed film thicknesses with those calculated from eq 5 . The results of this comparison are presented in table 5 . It will be noted that practically all the residuals are within \pm 3 percent of the computed values. This is thought to be within the limits of experimental error for the apparatus used.

TABLE 5.-Comparison of computed and observed film thicknesses

\begin{tabular}{|c|c|c|c|c|c|c|c|c|c|c|}
\hline \multirow[b]{2}{*}{ Length } & \multirow{2}{*}{$\begin{array}{l}\text { Ap- } \\
\text { proxi- } \\
\text { mate } \\
\text { speed }\end{array}$} & \multicolumn{9}{|c|}{$\begin{array}{l}\text { Percentage deviation of observed film thickness from that computed from } \\
\text { eq. } 5\end{array}$} \\
\hline & & $\begin{array}{l}\text { Min- } \\
\text { eral } \\
\text { oil } 1\end{array}$ & $\begin{array}{l}\text { Min- } \\
\text { eral } \\
\text { oil } 2\end{array}$ & $\begin{array}{l}\text { Min- } \\
\text { eral } \\
\text { oil 3 }\end{array}$ & $\begin{array}{l}\text { Min- } \\
\text { eral } \\
\text { oil } 4\end{array}$ & $\begin{array}{c}\text { Di- } \\
\text { butyl } \\
\text { phtha- } \\
\text { late }\end{array}$ & $\begin{array}{l}\text { Aro- } \\
\text { clor }\end{array}$ & $\begin{array}{c}\text { Pea- } \\
\text { nut oil }\end{array}$ & $\begin{array}{c}\text { Sperm } \\
\text { oil }\end{array}$ & $\begin{array}{c}\text { Lard } \\
\text { oil }\end{array}$ \\
\hline $\mathrm{cm}$ & $\left\{\begin{array}{c}c \mathrm{~m} / \mathrm{sec} \\
0.110 \\
.170 \\
.265 \\
.400 \\
.600 \\
.930 \\
1.42\end{array}\right.$ & $\begin{array}{r}+3.1 \\
-0.1 \\
-1.5 \\
-1.3 \\
+0.5 \\
+.3 \\
+.4\end{array}$ & $\begin{array}{r}+0.7 \\
+.2 \\
-.4 \\
+.6 \\
+.1 \\
+.2 \\
-.5\end{array}$ & $\begin{array}{r}-0.1 \\
-.2 \\
+.4 \\
+.2 \\
+.2 \\
-.1 \\
-1.4\end{array}$ & $\begin{array}{r}-0.4 \\
.0 \\
-.5 \\
+4.0 \\
+3.0 \\
+0.9 \\
-.2\end{array}$ & $\begin{array}{r}+0.9 \\
-.4 \\
-1.5 \\
-0.6 \\
+.1 \\
+.1 \\
+1.1\end{array}$ & $\begin{array}{r}+0.2 \\
-.3 \\
-.4 \\
+.7 \\
+.7 \\
+1.3 \\
-0.5\end{array}$ & $\begin{array}{r}+0.8 \\
+.2 \\
+.6 \\
+.7 \\
+.2 \\
-1.1 \\
-1.8\end{array}$ & $\begin{array}{r}+0.1 \\
+.8 \\
+.8 \\
+.4 \\
+.1 \\
+.4 \\
-.2\end{array}$ & $\begin{array}{r}-0.6 \\
-.3 \\
-.2 \\
+.8 \\
+.9 \\
+1.0 \\
-0.7\end{array}$ \\
\hline $15 \ldots$ & $\left\{\begin{array}{c}0.110 \\
.170 \\
.265 \\
.400 \\
.600 \\
.930 \\
1.42\end{array}\right.$ & $\begin{array}{r}.0 \\
+.1 \\
-.3 \\
+1.1 \\
+0.1 \\
-.1 \\
-.3\end{array}$ & $\begin{array}{r}-.1 \\
-.6 \\
-.5 \\
+2.0 \\
+.7 \\
+.1 \\
-.4\end{array}$ & $\begin{array}{r}-0.9 \\
-.6 \\
+.8 \\
+1.4 \\
0.0 \\
+.2 \\
-1.1\end{array}$ & $\begin{array}{r}+.1 \\
+.1 \\
+.7 \\
+1.7 \\
+1.2 \\
+0.3 \\
-1.7\end{array}$ & $\begin{array}{r}+2.4 \\
+0.2 \\
-1.1 \\
-1.6 \\
-0.7 \\
+.2 \\
+1.1\end{array}$ & $\begin{array}{r}-.1 \\
-.2 \\
+.1 \\
+.2 \\
+.3 \\
-.1 \\
-.6\end{array}$ & $\begin{array}{r}-0.7 \\
-.8 \\
.0 \\
+.6 \\
+.6 \\
+.6 \\
.0\end{array}$ & $\begin{array}{r}-.1 \\
+.6 \\
.0 \\
+.3 \\
+.4 \\
+.3 \\
-.2\end{array}$ & $\begin{array}{r}-.4 \\
-.8 \\
-.2 \\
.0 \\
+.3 \\
+.3 \\
-.4\end{array}$ \\
\hline 25 & $\left\{\begin{array}{r}0.110 \\
.170 \\
.260 \\
.400 \\
.600 \\
.930 \\
1.42\end{array}\right.$ & $\begin{array}{r}+2.1 \\
0.0 \\
+.4 \\
-.2 \\
-.2 \\
+.5 \\
+.3\end{array}$ & $\begin{array}{l}+.3 \\
+.1 \\
+.9 \\
-.1 \\
-.2 \\
-.1 \\
-.4\end{array}$ & $\begin{array}{r}-0.7 \\
-.8 \\
+1.0 \\
+0.9 \\
.0 \\
+.3 \\
-1.1\end{array}$ & $\begin{array}{r}+0.6 \\
-.9 \\
+.7 \\
+2.1 \\
+1.5 \\
+0.2 \\
-1.0\end{array}$ & $\begin{array}{r}+0.5 \\
-.3 \\
-1.7 \\
-1.9 \\
-0.9 \\
-.1 \\
+.5\end{array}$ & $\begin{array}{r}+.1 \\
+.8 \\
+.3 \\
-.1 \\
+.3 \\
-.1 \\
.0\end{array}$ & $\begin{array}{r}-.4 \\
-.8 \\
+.2 \\
+.4 \\
+.7 \\
-.3 \\
+.1\end{array}$ & $\begin{array}{r}-.4 \\
-.1 \\
+.1 \\
+.2 \\
-.1 \\
+.4 \\
+.2\end{array}$ & $\begin{array}{r}+1.5 \\
+0.9 \\
+.7 \\
+.1 \\
+.1 \\
+.2 \\
-.2\end{array}$ \\
\hline
\end{tabular}

When these experimental results are applied to physical apparatus in which the surface in question is not removed from the liquid bath, the equation is simplified because the capillary elevation remains the same at the beginning and end of the motion. Under these conditions the equation

$$
t=k(\nu s)^{n}
$$

will represent the average film thickness as long as the moving surface is kept in uniform motion or at the instant the motion stops. 


\section{CONCLUSIONS}

This experiment has demonstrated that over the range of viscosities and speeds used, the assumptions upon which Goucher and Ward based their derivation of the equation for the thickness of the film are incorrect, since the exponent of $\nu s$ is certainly higher than the one-half power. On the other hand, Jefferys' equation is neither confirmed nor disputed, since this experiment is incapable of specifying what film profile was obtained. It should be noted, however, that the mean ordinate of a parabolic section is two-thirds of the maximum ordinate of that section. Therefore Jefferys' solution would be possible if the thickness of the film near the surface of the oil bath remained constant independent of the length withdrawn.

Although the results presented here are obviously sufficiently exact for computing the small correction necessary in calibrating gasmeasuring standards, no satisfactory correlation of the equation constants with the other properties of the liquids has been found, and it is hoped that further studies can be conducted which may reveal the factors which govern the formation of the film.

The writer is greatly indebted to the late Edgar Buckingham for many helpful suggestions concerning this problem.

Washington, June 14, 1940. 